\title{
然 \\ ASSEMBLEIAS LEGISLATIVAS DO PARÁ E DO AMAZONAS EM ESTUDO COMPARADO: AÇÕES EFETIVAS DE ENFRENTAMENTO À PANDEMIA DE COVID-19
}

\author{
PARÁ AND AMAZONAS LEGISLATIVE ASSEMBLIES IN A COMPARATIVE \\ STUDY: EFFECTIVE ACTIONS TO FACE THE COVID-19 PANDEMIC
}

\author{
ASAMBLEAS LEGISLATIVAS DE PARÍS Y AMAZONAS EN UN ESTUDIO \\ COMPARATIVO: ACCIONES EFECTIVAS PARA ENFRENTAR LA \\ PANDEMIA DEL COVID-19
}

\author{
Rodolfo Silva Marques ${ }^{1}$ \\ Breno Rodrigo de Messias Leite ${ }^{2}$
}

\begin{abstract}
Resumo: Em março de 2020, o Brasil passou a conviver com a pandemia de Covid-19, gerando reflexões e reações efetivas por parte dos gestores públicos no contexto de enfrentamento a ela. Nesse contexto, em virtude da emergência da situação, o poder legislativo ganha protagonismo, com proatividade no relacionamento com os outros poderes e no atendimento das demandas da população. Aqui, faz-se uma análise do período entre março e agosto de 2020 (meses críticos da primeira onda pandêmica), a partir de duas assembleias legislativas, as do Pará e do Amazonas - estados da Região Norte e maiores unidades federativas do país. Usam-se os caminhos metodológicos da revisão de literatura e do estudo comparado. Como conclusões, identificam-se que as duas assembleias buscaram ações rápidas para o combate à crise, com uma relação mais equilibrada entre executivo e legislativo no Pará e conflitos entre os dois poderes no Amazonas.
\end{abstract}

Palavras-chave: Pandemia; Poder Legislativo; Pará; Amazonas; Estudo Comparado.

\begin{abstract}
In March 2020, Brazil started to live with the Covid-19 pandemic, generating reflections and effective reactions on the part of public managers in the context of facing it. In this context, due to the emergence of the situation, the legislative power gains prominence, with proactivity in the relationship with other powers and in meeting the demands of the population. Here, an analysis is made of the period between March and August 2020 (critical months of the first pandemic wave), from two legislative assemblies, those of Pará and Amazonas - states of the North Region and the largest federative units in the country. Methodological paths of literature review and comparative study are used. As conclusions, it is identified that the two assemblies sought quick actions to fight the crisis, with a more balanced relationship between the executive and the legislature in Pará and conflicts between the two powers in Amazonas.
\end{abstract}

Keywords: Pandemic; Legislative Power; Pará; Amazonas; Comparative Study.

\footnotetext{
${ }^{1}$ Professor-Doutor dos Cursos de graduação e de pós-graduação da Universidade da Amazônia (UNAMA) e de cursos de graduação da Faculdade de Estudos Avançados do Pará (FEAPA). Doutor em Ciência Política pela Universidade Federal do Rio Grande do Sul (UFRGS); Mestre em Ciência Política pela Universidade Federal do Pará (UFPA).

${ }^{2}$ Professor do curso de Relações Internacionais da Faculdade La Salle (AM). Mestre em Ciência Política pela Universidade Federal do Pará (UFPA).
} 
Resumen: En marzo de 2020, Brasil comenzó a convivir con la pandemia de Covid-19, generando reflexiones y reacciones efectivas por parte de los gestores públicos en el contexto de enfrentarla. Debido al surgimiento de la situación, el poder legislativo gana protagonismo, con proactividad en la relación con otros poderes y en la atención de las demandas de la población. Aquí se analiza el período comprendido entre marzo y agosto de 2020 (meses críticos de la primera ola pandémica), de dos asambleas legislativas, las de Pará y Amazonas, estados de la Región Norte y las mayores unidades federativas del país. Se utilizan rutas metodológicas de revisión de la literatura y estudio comparativo. Como conclusiones, se identifica que las dos asambleas buscaron acciones rápidas para combatir la crisis, con una relación más equilibrada entre el ejecutivo y el legislativo en Pará y conflictos entre los dos poderes en Amazonas.

Palabras llave: Pandemia; Poder Legislativo; Para; Amazonas; Estudio comparativo.

\section{Introdução}

A pandemia da covid-19, assim nomeada pela Organização Mundial da Saúde (OMS) em março de 2020, atingiu, praticamente, de forma diferenciada e com algumas sazonalidades, todos os continentes do mundo (PORTAL SAÚDE ABRIL, 2020). Há um grande desafio, em vários níveis, em entender a crise sanitária com todas as implicações políticas, econômicas, comportamentais. A partir de março de 2020 - sendo que o primeiro caso confirmado foi divulgado em 26 de fevereiro -, o Brasil passou a conviver de forma intensa com o cenário da pandemia da covid-19. Tal contexto trouxe muitas reflexões - e dúvidas - por parte da população brasileira e despertou reações efetivas pelos gestores públicos para gerar um processo de enfrentamento do novo coronavírus.

Até a primeira quinzena de setembro, o Brasil já havia ultrapassado as marcas de 4 milhões e 200 mil contaminados e 130 mil mortes - e a maior parte das unidades federativas já havia alcançado um cenário de estabilidade, até mesmo com os números em queda, na chamada primeira onda da doença. Todavia, os dados ainda apontavam altos índices de contaminação e de mortes a partir da metodologia das médias móveis (600 a 800 óbitos diários, com letalidade de $3,1 \%)^{3}$.

No cenário brasileiro, importa para a pesquisa acadêmica identificar as ações dos gestores e legisladores no sentido de identificar prioridades e responder, de maneira efetiva, aos cenários de crise e às demandas da população, considerando tanto as premissas do accountability quanto de responsiveness.

No cenário brasileiro, importa para a pesquisa acadêmica identificar as ações dos gestores e legisladores no sentido de identificar prioridades e responder, de maneira efetiva, aos cenários de crise e às demandas da população, considerando tanto as premissas do accountability quanto de responsiveness.

\footnotetext{
${ }^{3}$ No final de fevereiro de 2021, o Brasil vivia a segunda onda da pandemia, com mais de 10,5 milhões de casos confirmados e aproximadamente 255 mil mortes. Informações disponíveis em https://covid.saude.gov.br/. Acesso: 28 fev. 2021.
} 
Assim, considerando-se a emergência da situação em todo o país, os poderes legislativos constituídos apresentam protagonismo, com uma atuação destacada e, de certa forma, proativa com os outros poderes da República - com a necessidade iminente de atender às demandas emergenciais de saúde pública da sociedade, considerando-se a urgência e a complexidade do tema (ARAÚJO FILHO, 2019).

Como casos de análise, a escolha é por uma análise comparada entre as ações dos poderes legislativos estaduais de duas unidades subnacionais do Brasil - Pará e Amazonas. Tais estados guardam as semelhanças principais de serem os dois maiores estados do Brasil em extensão territorial - Amazonas possui $1.571 .000 \mathrm{~km}^{2}$ e Pará 1.248.000 km² -, mas também apresentaram diferenças durante o processo de enfrentamento à pandemia. O período selecionado para a análise das ações legislativas foi o de março até agosto de 2020.

Assim, neste artigo, há a seguinte distribuição dos conteúdos: a) uma operacionalização de alguns conceitos; b) o caso do Pará; c) o caso do Amazonas; d) estudo comparado e; e) conclusões.

\section{Operacionalização Conceitual}

Dentro da presente discussão a respeito das ações legislativas estaduais no contexto da pandemia da Covid-19, trabalha-se, aqui, com algumas categorias conceituais para dar suporte aos dados expostos. Duas das ideias que precisam ser resgatadas são as de accountability e responsiveness, intimamente ligadas à capacidade de ação dos poderes legislativos diante do cenário em tela.

Accountability, dentro da gestão pública converte-se como essencial, principalmente no âmbito dos trabalhos legislativos, dos governos e da sociedade, que buscam identificar se os recursos públicos são usados de forma adequada e administrados de acordo com as leis vigentes e regulamentos constituídos; se os programas de governo estão sendo, portanto, administrados de forma eficiente, eficaz e respeitando o princípio da economicidade (GAO, 2005; SIU, 2011).

De acordo com O’Donnell (1998), a prestação de contas e a transparência da gestão pública são questões inerentes à ideia de accountability, mesmo que essa relação entre os poderes possa apresentar conflitos. Ela pode ser visualizada das direções da horizontalidade e da verticalidade: há accountability horizontal quando há a prestação de contas em um mesmo nível, de entidade para entidade, como entre os poderes de uma República (legislativo e executivo, por exemplo); na direção da accountability vertical, há uma cobrança de responsabilidade por parte de quem recebe os recursos disponibilizados - o povo, questionando as ações do governo e das assembleias legislativas. 
Nesse mesmo ambiente de discussão a respeito das ações de enfrentamento à pandemia da Covid-19 no Brasil, emerge a ideia da responsiveness. De acordo com Moisés (2010), este conceito está ligado à ideia de que gestores públicos e instituições devem ter atuação efetiva para o atendimento dos anseios sociais, de forma antecipada - e sem gerar frustrações no público.

De acordo com Martines Júnior (2016), a administração pública deve ter, de forma inerente, um foco de ações rápidas para atender as necessidades dos cidadãos. Em um contexto como o da pandemia, os conceitos de accountability e responsiveness estão intimamente ligados no conjunto de ações dos poderes executivo e legislativo. Soma-se ainda às essas definições o debate sobre o pacto federativo e o federalismo, em especial na distribuição de recursos públicos e das prioridades da gestão no âmbito dos estados e municípios.

De acordo com Höffe (2005), é possível entender o pacto federativo como a União de entes federados, com estes possuindo autonomia e vinculados ao poder central. Esses entes federados realizam alianças para a formação do governo central, que, por sua vez, assume um grau maior de atribuições e responsabilidades, com as unidades (estaduais, como no caso brasileiro), assumindo responsabilidades nacionais, como a definição da política externa, a defesa nacional contra ameaças estrangeiras, serviços de telecomunicações, entre outros.

Dentro do pacto federativo e do federalismo brasileiros, as unidades subnacionais seguem uma regra majoritária, com um Poder Executivo central e os poderes legislativos e judiciários comuns. Segundo Arrechte (2002), o sistema federalista se mostra, pois, como um modo de organização no qual os entes federados possuem autonomia financeira, tributária e políticoadministrativa para garantir o equilíbrio que se forma, entre eles, para a constituição do Estado Federal. Na federação brasileira, por sua vez, os estados-membros guardam autonomia - mas não soberania, já que esta cabe à União. Os governos locais, assim, concedem ao poder centralizado algumas prerrogativas em troca de aumento da capacidade diplomática e/ou militar, consolidando um pacto institucional e constitucional (BRASIL, 1988).

Soares (1997) destaca que o contrato entre unidades federativas e o poder central indica que as comunidades repassam parte de seus poderes para uma unidade política nacional, a partir de consensos e garantias de autonomias e de responsabilidades divididas para cada ente federativo. Na Constituição Federal do Brasil, há a premissa do Estado Democrático de Direito, como uma união indissociável de Estados, do Distrito Federal e dos Municípios, com o compromisso de respeitar a pluralidade de interesses que há na sociedade através dos processos de participação política.

Nesse contexto, portanto, as ações de combate à pandemia no Brasil deveriam ser coordenadas a partir do governo federal com suporte financeiro para as unidades federativas. Governadores, prefeitos, deputados estaduais e vereadores acabaram adquirindo protagonismo, mostrando, uma vez mais, certa fragilidade do presidente da República no gerenciamento do pacto federativo e na estratégia nacional de enfrentamento à Covid-19. 
No dia 16 de abril de 2020, aliás, o Supremo Tribunal Federal (STF) deliberou pela autonomia a prefeitos e governadores nas definições a respeito das medidas de enfrentamento ao novo coronavírus - e de restrição à circulação das pessoas. Como se percebe na análise de Alves, Ramos e Delduque (2020), estados e municípios ficaram, assim, responsáveis por regulamentar as medidas de distanciamento social e de controle de protocolos sanitários aplicados à comunidade. Na verdade, a decisão apenas corroborou o que já estava previsto na Carta Magna de 1988 (BRASIL, 2020).

Outro fato relevante dessa discussão foi a decretação dos estados de emergência e de calamidade pública no país em relação às consequências do rápido e progressivo crescimento da infecção comunitária. Só nos meses de fevereiro e março de 2020, o Congresso Nacional aprovou, sucessivamente, após encaminhamento do governo federal, tais estados, a partir dos efeitos da pandemia.

Em fevereiro de 2020, a Emergência em Saúde Pública de Importância Nacional foi declarada pelo Ministério da Saúde por meio da Portaria ${ }^{\circ} 188 / 2020$, depois de a OMS ter declarado Emergência em Saúde Pública de Importância Internacional, em 30 de janeiro de 2020. A medida tomada pelo ministério levou em consideração a complexidade dos efeitos da disseminação do novo coronavírus e a necessidade de respostas coordenadas, com ações de prevenção e controle de danos à saúde pública ${ }^{4}$.

Nesse mesmo contexto, o governo federal redigiu e o Congresso Nacional aprovou a Lei $\mathrm{n}^{\mathrm{o}}$ 13.979/2020, em março, com medidas de enfrentamento à emergência e a seus efeitos. A lei também está em vigor enquanto vigorar a emergência em saúde, considerando-se o aumento de gastos orçamentários. O Congresso também aprovou o pedido do reconhecimento do estado de calamidade pública e publicou o Decreto Legislativo n 6/2020. O estado de calamidade vai até 31 de dezembro de $2020^{5}$.

E coube, ainda, aos poderes legislativos estaduais, em suas interações com os respectivos governos, buscar ações emergenciais e essenciais para o combate à pandemia da Covid-19. Tais discussões, marcadas pelo conflito redistributivo, nas observações de Limongi e Figueiredo (2005), fazem parte do processo democrático e da busca de protagonismo por parte dos poderes constituídos, para além de uma responsabilidade permanente de priorizar os interesses coletivos.

Assim, a partir dessa operacionalização conceitual e da exposição de algumas peculiaridades do cenário brasileiro em relação à pandemia, passar-se-ão às análises das ações legislativas contra a pandemia nos estados do Pará e do Amazonas.

\footnotetext{
${ }^{4}$ A duração da situação decretada é indeterminada - a partir também das definições da Organização Mundial da Saúde. Informações disponíveis em https://agenciabrasil.ebc.com.br/saude/noticia/2020-03/emergencia-em-saude-e-estadode-calamidade-veja-diferenca. Acesso em 09 set. 2020.

${ }^{5}$ Idem
} 


\section{Desenho de pesquisa}

A proposta metodológica deste artigo é fazer um estudo descritivo (DIEHL; TATIM, 2004) a partir da literatura disponível sobre os estudos legislativos, de fatos específicos relativos à pandemia de Covid-19 e às ações legislativas no Pará e no Amazonas neste ano.

Utiliza-se o recurso do estudo comparado (GONZÁLEZ, 2008), a partir de dois casos com condições similares (duas grandes unidades federativas, vizinhos da região norte e com condições naturais parecidas), com desempenhos um pouco diferentes em relação ao objeto em questão.

Além do mais, exploram-se a base de dados e os relatórios técnicos sobre a produção legislativa dos dois estados e lá constatamos uma mudança substantiva no modo de proceder a organização dos trabalhos legislativos. Em consonância com os protocolos de segurança sanitária, os políticos saíram de dentro das casas legislativas e passaram a atuar de modo remoto, via serviços de teleconferência e intensificando ainda mais os trabalhos nas redes sociais nas suas respectivas bases eleitorais.

Os dados computados nesta pesquisa relatam intensa produção legislativa no período da pandemia sem, contudo, deixar de lado a capacidade de fiscalização e controle dos governadores e de seus secretários de saúde. Indicadores sobre a evolução da pandemia e protocolos das autoridades de saúde igualmente foram mobilizados na elaboração da análise desta pesquisa.

A pesquisa tem natureza qualitativa, pois utilizamos essencialmente a base de dados produção legislativa - sobre a pandemia e as reações possíveis do Legislativo vis-à-vis os poderes proativos dos governadores. À luz desse substrato empírico, resolvemos correlacionar o amplo processo de check and balances, o poder de controle do legislativo ou mesmo a ocorrência de predomínio de um sobre o outro.

Como problema de pesquisa, estabelece a seguinte questão: como os poderes legislativos dos dois principais estados da região Norte, com suas semelhanças e peculiaridades, criaram ações efetivas de combate à pandemia de Covid-19?

Parte-se da hipótese de que o funcionamento efetivo do Poder Legislativo, no âmbito dos estados, tende a contribuir para ações em momentos de emergência - como o da pandemia de Covid-19, nesse ano de 2020.

Como objetivos do trabalho, a ideia é identificar como os Legislativos atuaram em relação à pandemia, nos estados do Pará e do Amazonas e, ao mesmo tempo, propor uma discussão sobre o posicionamento do Legislativo em relação ao Executivo em ambos os estados, no contexto da emergência e nos sistemas de freios de contrapesos no campo institucional.

Nesse sentido, mesmo considerando a relevância de se discutir a postura dos chefes do Poder Executivo no combate à pandemia, a perspectiva, aqui, é avaliar as ações dos legisladores e seus comportamentos e ações de enfrentamento combate à Covid-19. 
Opta-se, assim, por uma discussão acerca dos legislativos estaduais, a partir das interações com o Poder Executivo e das decisões tomadas dentro das Assembleias Legislativas nas referidas unidades federativas.

\section{O Caso do Pará}

Durante o período da pandemia analisada neste trabalho, o poder legislativo do Pará agiu de forma rápida - e, geralmente, em consonância com o Executivo. Adotou, entre abril e agosto de 2020, o plenário virtual para as sessões, à semelhança do que ocorreu com a Câmara dos Deputados e com o Senado Federal ${ }^{6}$.

A seguir, a tabela, em ordem cronológica, com algumas das principais ações da Assembleia Legislativa do Pará (ALEPA) no contexto de enfrentamento da Covid-19.

Tabela 1 - Principais ações da ALEPA no enfrentamento da Covid-19

\begin{tabular}{|c|c|c|c|}
\hline DATA & NOTÍCIA & $\begin{array}{l}\text { PRINCIPAIS DECISÕES } \\
\text { APROVADAS NA ALEPA }\end{array}$ & LINK DA NOTÍCIA \\
\hline 07.04 .2020 & $\begin{array}{l}\text { Deputados instalam } \\
\text { Comissão } \\
\text { Parlamentar para } \\
\text { fiscalizar ações do } \\
\text { Executivo no } \\
\text { combate à } \\
\text { pandemia }\end{array}$ & $\begin{array}{l}\text { - Instalação da Comissão } \\
\text { Parlamentar para acompanhar a } \\
\text { situação fiscal e a execução } \\
\text { orçamentária e financeira das } \\
\text { medidas, adotadas no Pará e } \\
\text { relacionadas à pandemia de Covid- } \\
\text { 19). A Comissão é tida como } \\
\text { instrumento de trabalho legislativo } \\
\text { com poderes para fiscalizar as } \\
\text { ações desenvolvidas pelo Poder } \\
\text { Executivo e os investimentos de } \\
\text { recursos financeiros. Os integrantes } \\
\text { da comissão foram os deputados } \\
\text { Antônio Tonheiro (PL), Wanderlan } \\
\text { Quaresma (MDB), Eliel Faustino } \\
\text { (DEM), Iran Lima (MDB), (MDB) } \\
\text { e Victor Dias (PSDB). }\end{array}$ & $\begin{array}{l}\text { www.alepa.pa.gov.br/noti } \\
\text { cia/3889/. Acesso em } 10 \\
\text { ago. } 2020 \text {. }\end{array}$ \\
\hline 15.04 .2020 & $\begin{array}{l}\text { Deputados aprovam } \\
\text { projetos para } \\
\text { atender ações de } \\
\text { combate à } \\
\text { pandemia }\end{array}$ & $\begin{array}{l}\text { - Aprovação de três projetos de } \\
\text { autoria do Poder Executivo e } 10 \\
\text { Decretos Legislativos de } \\
\text { Calamidade Pública para } \\
\text { Abaetetuba, Anapu, Belterra, } \\
\text { Gurupá, Mocajuba, Placas, } \\
\text { Paragominas, Ourém, Itaituba e } \\
\text { Dom Eliseu. } \\
\text { - Aprovação de projeto de Lei } \\
\text { Complementar No } 4 / 2020 \text { (de } \\
\text { autoria do Executivo), que altera a } \\
\text { Lei Complementar Estadual no } 07 \text {, }\end{array}$ & $\begin{array}{l}\text { www.alepa.pa.gov.br/noti } \\
\text { cia/3906/. Acesso em } 10 \\
\text { ago. } 2020 \text {. }\end{array}$ \\
\hline
\end{tabular}

\footnotetext{
${ }^{6}$ E, em 17 de março de 2020, ainda nos encontros presenciais, os deputados usaram a tribuna para falar da pandemia da covid-19 e ressaltaram que o Brasil não estava preparado para enfrentar o novo coronavírus. Informações disponíveis em www.alepa.pa.gov.br/noticia/3833/. Acesso em: 15 ago. 2020.
} 


\begin{tabular}{|c|c|c|c|}
\hline & & $\begin{array}{l}\text { de } 25 \text { de setembro de } 1991 \text {, que } \\
\text { regula o art. } 36 \text { da Constituição do } \\
\text { Estado do Pará, sobre contratação } \\
\text { temporária. } \\
\text { - Aprovação do Projeto de Lei } \\
\text { 80/2020, que abre concessão de } \\
\text { Crédito Especial no valor de até R\$ } \\
800 \text { milhões para criar a ação } \\
\text { orçamentária COVIDPARÁ. }\end{array}$ & \\
\hline 29.04 .2020 & $\begin{array}{l}\text { ALEPA aprova } \\
\text { projetos de } \\
\text { combate à } \\
\text { pandemia }\end{array}$ & $\begin{array}{l}\text { - Obrigatoriedade das pessoas de } \\
\text { usarem máscaras ao transitar nas } \\
\text { ruas (Projeto 101/2020, do } \\
\text { deputado Carlos Bordalo/PT-PA). } \\
\text { - Obrigatoriedade do uso de } \\
\text { máscaras em ambientes de trabalho } \\
\text { (Projeto 86/2020, do deputado } \\
\text { Carlos Bordalo/PT-PA). } \\
\text { - Obrigatoriedade das instituições } \\
\text { financeiras instaladas em fornecer } \\
\text { em suas agências e postos de } \\
\text { atendimento de forma gratuita, } \\
\text { álcool em gel e máscaras de } \\
\text { proteção a todos os clientes e } \\
\text { usuários (Projeto 89/2020, da } \\
\text { deputada Cilene Couto/PSDB-PA). } \\
\text { - Obrigatoriedade de emissão de } \\
\text { senhas no atendimento presencial } \\
\text { para evitar aglomerações nas } \\
\text { agências bancárias (Projeto } \\
\text { 88/2020, do deputado Victor } \\
\text { Dias/PSDB-PA) } \\
\text { - Restrição de pessoas em velórios } \\
\text { e sepultamentos no Pará no período } \\
\text { da pandemia causada pelo COVID- } \\
\text { 19. O projeto foi da deputada Nilse } \\
\text { Pinheiro/Republicanos-PA }\end{array}$ & $\begin{array}{l}\text { www.alepa.pa.gov.br/noti } \\
\text { cia/3933. Acesso em } 10 \\
\text { ago. } 2020 \text {. }\end{array}$ \\
\hline 30.04 .2020 & $\begin{array}{c}\text { Procuradoria } \\
\text { Especial da Alepa } \\
\text { faz live sobre a } \\
\text { violência contra a } \\
\text { mulher na } \\
\text { pandemia }\end{array}$ & $\begin{array}{l}\text { - Realização da live "Mulher e os } \\
\text { desafios em período de pandemia", } \\
\text { com a deputada Nilse Pinheiro e a } \\
\text { presidente da Comissão da Mulher } \\
\text { da OAB/PA, Natasha Vasconcelos. } \\
\text { Foi abordada a preocupação com a } \\
\text { violência doméstica no contexto da } \\
\text { pandemia. }\end{array}$ & $\begin{array}{l}\text { www.alepa.pa.gov.br/noti } \\
\text { cia/3942/. Acesso em } 10 \\
\text { ago. } 2020 \text {. }\end{array}$ \\
\hline
\end{tabular}

\footnotetext{
${ }^{7}$ No dia 29 de abril de 2020, além dos projetos de lei de autoria dos parlamentares que foram validados, foram aprovados 35 decretos que declaram o estado de Calamidade Pública para enfrentamento da pandemia. Receberam votos favoráveis para atender os municípios Acará, Alenquer, Almeirim, Anajás, Aveiro, Baião, Bagre, Bannach, Benevides, Cametá, Colares, Curralinho, Cachoeira do Piriá, Goianésia do Pará, Limoeiro do Ajuru, Mãe do Rio, Medicilândia, Nova Ipixuna, Novo Progresso, Monte Alegre, Óbidos, Pacajá, Parauapebas, Pau D'Arco, Primavera, Porto de Moz, Rondon do Pará, Rurópolis, Senador José Porfírio, Tomé Açu, Uruará, Santa Cruz do Arari, Santa Bárbara, Santarém Novo e Viseu. Com a aprovação, os municípios poderiam ampliar verbas para atender as medidas de contenção da Covid-19, em virtude dos problemas de saúde pública e econômicos gerados pelo enfrentamento da pandemia decorrente do coronavírus. Os decretos de estado de calamidade passaram a vigorar após publicação no Diário Oficial. Informações disponíveis em: www.alepa.pa.gov.br/noticia/3933/. Acesso em: 10 ago. 2020.
} 


\begin{tabular}{|c|c|c|c|}
\hline 06.05 .2020 & $\begin{array}{c}\text { Alepa aprova } \\
\text { empréstimo para } \\
\text { combater pandemia } \\
\text { e estabelece multa } \\
\text { para fake news }{ }^{8}\end{array}$ & $\begin{array}{l}\text { - Aprovação do projeto de lei } \\
112 / 2020, \text { de autoria do Poder } \\
\text { Executivo, que autoriza o Pará a } \\
\text { contratar operação de crédito } \\
\text { externo até o valor de US\$ } 100 \\
\text { milhões de dólares junto ao Banco } \\
\text { Mundial para aplicar investimen- } \\
\text { tos emergenciais ao projeto "Pará } \\
\text { Contra o Coronavírus"9. } \\
\text { - Aprovação do projeto de lei } \\
\text { 108/2020, de autoria do deputado } \\
\text { Gustavo Sefer/PSD-PA, que define } \\
\text { pontuação de bonificação em } \\
\text { concurso público no Pará aos } \\
\text { voluntários durante a pandemia. } \\
\text { - Aprovação do projeto de lei } 114 \\
\text { /2020, da deputada Dilvanda } \\
\text { Faro/PT-PA, estabelecendo multa } \\
\text { para quem divulgar "fake news" } \\
\text { sobre epidemias, endemias e } \\
\text { pandemias no Estado. } \\
\text { - Para aumentar leitos de UTIs na } \\
\text { rede particular de saúde, foi } \\
\text { aprovado o projeto de lei } 121 / 2020 \text {, } \\
\text { que dispõe sobre a obrigatoriedade, } \\
\text { em caráter excepcional, dos Planos } \\
\text { Privados de Assistência à Saúde a } \\
\text { apresentarem planos de expansão } \\
\text { de leitos, principalmente de UTIs. }\end{array}$ & $\begin{array}{l}\text { www.alepa.pa.gov.br/noti } \\
\text { cia/3963/. Acesso em } 10 \\
\text { ago.2020. } \\
\text { https://g1.globo.com/pa/p } \\
\text { ara/noticia/2020/05/07/al } \\
\text { epa-aprova-credito-para- } \\
\text { combate-a-pandemia-e- } \\
\text { estabelece-multa-para- } \\
\text { fake-news.ghtml. Acesso } \\
\text { em } 10 \text { ago.2020. }\end{array}$ \\
\hline 04.08 .2020 & $\begin{array}{c}\text { CCJ aprova } \\
\text { projetos de medidas } \\
\text { para a pandemia, } \\
\text { escalpelamento e } \\
\text { de combate a } \\
\text { violência feminina }\end{array}$ & $\begin{array}{l}\text { - Aprovação de proposições pela A } \\
\text { Comissão de Constituição, Justiça e } \\
\text { Redação (CCJ) da Alepa. Uma } \\
\text { delas (65/2020), proposta pelo } \\
\text { deputado Fabio Freitas, inclui na } \\
\text { cesta básica do povo paraense o } \\
\text { álcool em gel 70\%. } \\
\text { - Aprovação do PL 66/2020, } \\
\text { também de Fabio Freitas, e que } \\
\text { estabelece políticas de } \\
\text { cancelamento ou remarcação de } \\
\text { passagens intermunicipais em razão } \\
\text { do coronavírus. }\end{array}$ & $\begin{array}{l}\text { www.alepa.pa.gov.br/noti } \\
\text { cia/4232/. Acesso em } 10 \\
\text { ago. } 2020 \text {. }\end{array}$ \\
\hline 10.08 .2020 & $\begin{array}{l}\text { Dilvanda Faro } \\
\text { apresenta projetos } \\
\text { para enfrentamento }\end{array}$ & $\begin{array}{l}\text { - Apresentação, pela deputada } \\
\text { Dilvanda Faro/PT-PA, de matérias } \\
\text { para enfrentamento da pandemia no }\end{array}$ & $\begin{array}{l}\text { www.alepa.pa.gov.br/noti } \\
\text { ciadep/4248/115. Acesso } \\
\text { em } 10 \text { ago. } 2020 \text {. }\end{array}$ \\
\hline
\end{tabular}

${ }^{8}$ Na sessão de 6 de maio de 2020, o deputado Fábio Freitas/Republicanos-PA questionou a não-inclusão das atividades das igrejas como um serviço essencial à população nos dez municípios alcançados pelo decreto estadual $\mathrm{n}^{\circ} 729$ de 05.05.2020, estabelecendo o Lockdown. Os deputados Martinho Carmona/MDB-PA e Raimundo Santos/Patriota-PA, com histórico de militância religiosa tiveram posição similar à do parlamentar Fábio Freitas. Informações disponíveis em: https://g1.globo.com/pa/para/noticia/2020/05/07/alepa-aprova-credito-para-combate-a-pandemia-e-estabelecemulta-para-fake-news.ghtml. Acesso em: 10 ago. 2020.

${ }^{9}$ Com esse valor, superior a 400 milhões de reais, foram previstas ações de desenvolvimento de novas ferramentas de gestão para o sistema de vigilância epidemiológica, regulação de leitos, adoção de medidas que venham diminuir a taxa de mortalidade pelo coronavírus, entre outros processos que foram avaliados e propostos. As informações estão disponíveis em: https://g1.globo.com/pa/para/noticia/2020/05/07/alepa-aprova-credito-para-combate-a-pandemia-eestabelece-multa-para-fake-news.ghtml. Acesso em: 10 ago. 2020. 


\begin{tabular}{|c|l|l|l|}
\hline da pandemia no & Pará. Entre março a junho, foram & \\
Pará & protocolados moções, & \\
& requerimentos, projetos de & \\
& resolução, indicação e projeto de & \\
& lei. Entre elas, foi solicitada a & \\
& instalação de Hospital de & \\
& Campanha na Região de Integração & \\
& do Tocantins, em Cametá, no \\
& nordeste paraense, por exemplo. & \\
\hline
\end{tabular}

Fonte: Elaborada pelos autores, a partir de dados compilados.

Em 8 de abril, o deputado estadual Carlos Bordalo, apresentou seis propostas de ações emergenciais ao Governo do Estado para garantir a proteção de direitos básicos e constitucionais à população paraense ${ }^{10}$.

Em 15 de abril de 2020, ocorreu a primeira sessão ordinária online - um marco histórico - dentro das recomendações de distanciamento social em virtude da crise sanitária que atingia todo o país. A Assembleia Legislativa do Estado do Pará inaugurou, de forma oficial, o sistema de votação remota. Com seis horas de duração, a Sessão Extraordinária virtual foi conduzida pelo presidente do Legislativo Estadual, deputado Dr. Daniel Santos, fazendo uso da máscara de proteção. Houve ajustes jurídicos, tanto no Regimento Interno da Casa quanto na Constituição Estadual, para garantir os encontros dos parlamentares pelas plataformas digitais. No primeiro semestre de 2020, houve 24 sessões plenárias por videoconferências, além das reuniões das Comissões de Constituição e Justiça e Fiscalização Financeira e Orçamentária. No contexto da pandemia, entre abril e junho de 2020, a ALEPA aprovou 14 leis - sendo a maioria de autoria do Poder Executivo ${ }^{11}$.

Em 06 de maio, o protagonismo do Legislativo do Pará, em articulação com o Executivo, ficou muito claro, com a autorização para o governador Helder Barbalho em obter financiamento interno. Na mensagem encaminhada pelo Executivo ao Legislativo, o governador ressaltou que o Pará possuía plenas condições para contrair empréstimos para ações de enfrentamento à pandemia - e que uma decisão rápida da ALEPA seria importante, o que realmente acabou acontecendo. Na mesma data, houve a aprovação do estado de calamidade pública - desta vez, para 14 municípios: Jacareacanga, Brasil Novo, Santarém, Bujaru, Igarapé-Açu, Igarapé-Miri, Garrafão do Norte, Inhangapi, Bragança, Moju, Breves, São Sebastião da Boa Vista, Santa Maria do Pará e Cachoeira do Arari.

\footnotetext{
${ }^{10}$ Entre as propostas, o apoio ao trabalho de comunicadores populares, a disponibilização de máscaras de tecido aos moradores das periferias e a suspensão de custos tributários nos produtos da cesta básica, entre outros. Informações disponíveis em: www.alepa.pa.gov.br/noticiadep/3891/106. Acesso em: 15 ago. 2020.

${ }^{11}$ A legislação da Covid-19 também contou com projetos de autoria dos deputados Carlos Bordalo (Lei 9.051/2020), Victor Dias (Lei 9.053/2020), Gustavo Sefer (Lei 9.060/2020), Eliel Faustino (Leis 9.062/2020 e 9.065/2020), Delegado Toni Cunha (Lei 9.063/2020) e Paula Gomes (Lei 9.085/2020). Informações disponíveis em www.alepa.pa.gov.br/noticia/4207/. Acesso em: 5 set. 2020.
} 
No dia 15 de junho, as secretarias de Saúde e de Administração, juntamente com outros gestores públicos, participaram de reunião na comissão especial de deputados para o acompanhamento das despesas com ações de combate a pandemia por coronavírus. $\mathrm{O}$ encontro teve a presença do líder do governo na ALEPA, deputado Chicão/MDB-PA. Entre março e junho, de acordo com os dados oficiais, foram investidos $\mathrm{R} \$ 342$ milhões de reais em hospitais, equipamentos e ações para minimizar os impactos da pandemia na população, com os dados estando disponíveis no Portal Transparência da Covid-19².

No dia 14 de agosto, o deputado Raimundo Santos, ouvidor-geral da ALEPA, participou a live "Transparência em Debate", organizada pela Secretaria de Transparência da Câmara Federal. Os parlamentares do Pará e do Acre, na ocasião, mostraram como foi o funcionamento dos legislativos estaduais durante a pandemia, com o uso da internet para a realização das sessões e reuniões remotas ${ }^{13}$.

Avaliando-se essa trilha histórica e os fatos relatados dentro do período de análise desse trabalho, é possível depreender que o legislativo do Pará agiu em consonância com o governador do estado do Pará, Helder Barbalho (MDB) - e teve protagonismo e agilidade para tratar as questões urgentes de enfrentamento à pandemia.

Esse alinhamento desenhado entre dois poderes foi garantido pelo governador desde o início de seu mandato, em janeiro de 2019, a partir da construção de uma base parlamentar e da parceria com o presidente da ALEPA - deputado Daniel Santos (MDB). Essa convergência foi essencial para minimizar os danos da pandemia no Pará, principalmente entre março e abril mesmo que esses tenham sido bem altos, no geral.

Foi importante também o movimento do Legislativo do Pará em criar mecanismos de controlar o Executivo, principalmente em relação ao ordenamento de recursos, definição de prioridades e obtenção de empréstimos externos para a compra de equipamentos para os hospitais, como formas de reforçar as ideias de accountability e responsiveness (DUNN, 1999). Outro dado representativo do processo foi o processo das reuniões remotas e das deliberações pelas plataformas digitais, além da mobilização de boa parte do Parlamento estadual no período analisado.

\footnotetext{
${ }^{12}$ A Comissão Parlamentar foi criada no início da pandemia, para monitorar as ações do poder executivo Informações disponíveis em: www.alepa.pa.gov.br/noticiadep/4099/111. Acesso em: 5 set. 2020.

$13 \mathrm{O}$ deputado Raimundo Santos ressaltou que, ainda no mês de abril, a ALEPA se preocupou em aprovar o reconhecimento do estado de calamidade pública no Pará, estendido à quase totalidade dos 144 municípios paraenses. Informações disponíveis em: www.alepa.pa.gov.br/noticia/4282/. Acesso em: 5 set. 2020.
} 


\section{0 caso do Amazonas}

O Amazonas, em especial através dos poderes Executivo e Legislativo, enfrentou a pandemia com muitas dificuldades. A chegada do novo coronavírus ao maior estado da federação evidenciou que a falta de políticas permanentes de saúde e de coordenação estratégica na infraestrutura sanitária geraram o cenário propício para a propagação do vírus e o elevado número de mortes.

O estado possui algumas especificidades que devem ser levadas em consideração na avaliação das políticas de infraestrutura da saúde. O estado traz, em sua essência, todas as características de uma difícil e limitada realidade amazônica, com entraves logísticos (estradas, portos, aeroportos etc.), baixa densidade demográfica se comparada à imensidade territorial e maior população indígena do país (LEITE, 2020).

O crescimento de casos de contaminações e mortes pela Covid-19, no Amazonas, refletiu, em certa medida, uma desarticulação funcional das políticas públicas, com hospitais sobrecarregados, insuficiência de profissionais de saúde, falta de equipamentos médicos e ineficiência dos mecanismos de distanciamento social. A situação de quase colapso da saúde pública no estado mostrou, em última instância, um cenário de inabilidade administrativa, bem como algumas falhas do setor produtivo no Amazonas, com intensa concentração produtiva na região metropolitana de Manaus (LEITE, 2020).

A Assembleia Legislativa do Amazonas entrou no contexto do enfrentamento da Covid19 juntamente com o governo do estado e com outras instituições de fiscalização e controle. A elaboração de um Plano de Contingência apresentado ainda no mês de fevereiro de 2020 foi o passo inicial. Tal plano foi dividido em três etapas: a) Respostas Rápidas, com a elaboração de planos de ação dos municípios; b) Planos Municipais, com os municípios agindo a partir do contexto do estado; c) Fase de Atuação, com a identificação de pacientes acometidos pelo vírus e o registro da transmissão local.

O estado do Amazonas enfrentou muitas dificuldades no enfrentamento à pandemia, pela pouca quantidade de leitos/pacientes e de infraestrutura para o atendimento, pelos conflitos entre as demandas sanitárias e as atividades produtivas e pela baixa adesão da população em relação às orientações de distanciamento social (LEITE, 2020).

A tabela a seguir mostra, em ordem cronológica, com algumas das principais ações da Assembleia Legislativa do Amazonas (ALEAM) no contexto de enfrentamento da Covid-19. 
Tabela 2 - Principais ações da ALEAM no enfrentamento da Covid-19

\begin{tabular}{|c|c|c|c|}
\hline DATA & NOTÍCIA & $\begin{array}{c}\text { PRINCIPAIS DECISÕ̃S } \\
\text { APROVADAS NA ALEAM } \\
\end{array}$ & LINK \\
\hline 31.03 .2020 & $\begin{array}{l}\text { Aleam aprova por } \\
\text { unanimidade } \\
\text { calamidade pública } \\
\text { no Amazonas até } \\
31 \text { de dezembro } \\
\text { deste ano }\end{array}$ & $\begin{array}{l}\text { - Aprovação, pelo parlamento, por } \\
\text { unanimidade, do decreto do governador } \\
\text { Wilson Lima (PSC) de estado de } \\
\text { calamidade pública no Amazonas, que } \\
\text { vai até } 31 \text { de dezembro deste ano }\end{array}$ & $\begin{array}{l}\text { https://onjornal.com/al } \\
\text { eam-aprova-por- } \\
\text { unanimidade- } \\
\text { calamidade-publica- } \\
\text { no-amazonas-ate-31- } \\
\text { de-dezembro-deste- } \\
\text { ano/. Acesso em } 10 \\
\text { ago.2020. }\end{array}$ \\
\hline 28.04 .2020 & $\begin{array}{l}\text { Deputados } \\
\text { estaduais discutem } \\
\text { ações de combate à } \\
\text { pandemia no } \\
\text { Amazonas }\end{array}$ & $\begin{array}{l}\text { - Debate, durante sessão plenária } \\
\text { virtual, sobre as necessidades e ações } \\
\text { realizadas pelo Governo do Estado no } \\
\text { combate à pandemia causada pelo novo } \\
\text { coronavírus. O deputado João Luiz } \\
\text { (Republicanos), reiterou seu pedido } \\
\text { para que as igrejas sejam consideradas } \\
\text { serviços essenciais. }\end{array}$ & $\begin{array}{l}\text { https://diversidadeama } \\
\text { zonica.com.br/2020/0 } \\
\text { 4/28/deputados- } \\
\text { estaduais-discutem- } \\
\text { acoes-de-combate-a- } \\
\text { pandemia-no- } \\
\text { amazonas/. Acesso em } \\
10 \text { ago. } 2020 \text {. }\end{array}$ \\
\hline 06.05 .2020 & $\begin{array}{l}\text { Deputados aprovam } \\
\text { projeto que reabre } \\
\text { igrejas durante } \\
\text { pandemia no } \\
\text { Amazonas. }\end{array}$ & $\begin{array}{l}\text { - A Aleam aprovou a reabertura de } \\
\text { igrejas e templos religiosos por meio do } \\
\text { projeto de lei no } 136 / 2020 \text { de autoria do } \\
\text { deputado estadual } \quad \text { João } \\
\text { Luiz/Republicanos-AM, considerando } \\
\text { as igrejas como atividade essencial em } \\
\text { períodos de calamidade pública. }\end{array}$ & $\begin{array}{l}\text { https://noticias.uol.co } \\
\text { m.br/cotidiano/ultimas } \\
- \\
\text { noticias/2020/05/06/d } \\
\text { eputados-aprovam- } \\
\text { projeto-que-reabre- } \\
\text { igrejas-durante- } \\
\text { pandemia-no- } \\
\text { amazonas.htm. Acesso } \\
\text { em } 10 \text { ago.2020. }\end{array}$ \\
\hline 08.06 .2020 & $\begin{array}{l}\text { ALEAM ouve, } \\
\text { segunda (8), } \\
\text { comunidade } \\
\text { científica sobre } \\
\text { retorno das } \\
\text { atividades } \\
\text { presenciais }\end{array}$ & $\begin{array}{l}\text { - Realização de uma Audiência Pública } \\
\text { Virtual, proposta pelo deputado Josué } \\
\text { Neto (PRTB), para ouvir a comunidade } \\
\text { científica sobre o retorno das atividades } \\
\text { presenciais durante o fim da quarentena } \\
\text { e pico da pandemia do novo } \\
\text { coronavírus (Covid-19) no Estado. }\end{array}$ & $\begin{array}{l}\text { https://informeamazon } \\
\text { as.com.br/aleam- } \\
\text { ouve-segunda-8- } \\
\text { comunidade- } \\
\text { cientifica-sobre- } \\
\text { retorno-das- } \\
\text { atividades- } \\
\text { presenciais/. Acesso } \\
\text { em } 10 \text { ago.2020. }\end{array}$ \\
\hline
\end{tabular}

Fonte: Elaborada pelos autores, a partir de dados compilados.

No campo das relações entre Executivo e Legislativo no contexto da pandemia, em 24 de maio foi instalada a Comissão Parlamentar de Inquérito (CPI) da Saúde no Amazonas. O objeto da CPI foi investigar as acusações de irregularidades na aplicação de dinheiro público para a contratação de serviços e na formalização de contratos com empresas durante o auge da pandemia, por parte do governo estadual ${ }^{14}$.

\footnotetext{
${ }^{14} \mathrm{O}$ pedido de CPI foi protocolado pelo deputado estadual Péricles Rodrigues do Nascimento (PSL), em 30 de abril, com extensão do período de análise das questões da saúde entre 2011 e 2020. O presidente da ALEAM, Josué Neto (PSD), definiu que a CPI
} 
A ação da ALEAM emergiu após denúncias da imprensa, dos questionamentos do Tribunal de Contas do Estado e da postura do Ministério Público do Estado em apontar ilicitudes na compra de 28 respiradores pulmonares no valor de $\mathrm{R} \$ 2.970$ milhões, com a suspeita de superfaturamento. A CPI se estabeleceu com dois focos de investigação, transporte de ambulâncias e plantões médicos, além de suspeitas de superfaturamento na prestação dos serviços (LEITE, 2020).

Em 30 de junho de 2020 foi deflagrada a Operação Sangria, da Polícia Federal, com a apuração de práticas ilícitas como organização criminosa, corrupção e fraudes em processos licitatórios no enfrentamento da pandemia no estado do Amazonas. Houve a prisão preventiva da então secretária de saúde do estado, Simone Papaiz e do ex-secretário da pasta, João Paulo Marques dos Santos (LEITE, 2020).

A CPI da Saúde reforçou, nesse contexto, os grupos de oposição no estado, com o ressaltar das críticas à ineficiência do governo na estratégia de enfrentamento à pandemia. Nesse contexto, ganhou corpo o pedido de impeachment da chapa do governador Wilson Lima - posteriormente arquivado. Tanto a CPI da Saúde quanto a comissão de impeachment da chapa Wilson Lima e Carlos Almeida seguiram como processos distintos, porém complementares e, de certa forma, interdependentes (LEITE, 2020).

\section{Estudo comparado}

A partir do até aqui exposto, é possível identificar, no estudo comparado, que Pará e Amazonas mantiveram o padrão das unidades subnacionais brasileiras, buscando parcerias com o governo federal, dentro da premissa do pacto federativo, no sentido de equipar hospitais e ter recursos financeiros para dar suporte para as populações mais carentes. Todavia, houve uma perspectiva geral, em nível de semelhanças, assim como em relação às outras unidades federativas, em relação aos conflitos dos estados (governadores e assembleias legislativas) com o executivo federal.

O presidente Jair Bolsonaro (sem partido-RJ) adotou uma postura negacionista e entrou em choque com boa parte dos governadores e prefeitos, tanto em relação às medidas de distanciamento social quanto em relação à cessão de recursos públicos. $\mathrm{O}$ pacto federativo - e Pará e a Amazonas, como partes integrantes desse processo - ficou extremamente prejudicado pelo tratamento concedido pelo Executivo Federal ao enfrentamento da pandemia.

Os conceitos de accountability e responsiveness, na gestão pública e na atuação específica dos poderes legislativos dos estados do Pará e Amazonas se mostraram similares, tanto nas ideias da transparência e da prestação de contas quanto na busca de respostas mais rápidas para o atendimento das demandas sociais.

atendia os requisitos básicos para sua abertura regimental. Informações disponíveis em: www.terra.com.br/noticias/coronavirus/impeachment-de-governador-do-amazonas-e-aberto-naassembleia,11fbad80be9de880462d5dbfc96c6f05p0cgsuq8.html. Acesso em: 20 ago.2020. 
Nesse modelo de estudo comparado, em ciência política, de se elencar as semelhanças para encontrar as diferenças, é possível identificar, pelo menos, três pontos bem distintos das ações das assembleias legislativas do Pará e do Amazonas em relação ao enfrentamento da pandemia de Covid-19, entre março e agosto de 2020.

Um dos aspectos claros dessa diferenciação foi em relação às interações dos poderes Executivo e Legislativo. No Pará, a aliança entre o governador Helder Barbalho (MDB) e o presidente da ALEPA, Daniel Santos (MDB) foi essencial para a agilidade nas votações e na aprovação dos projetos do Executivo. O governador dispõe de maioria destacada no Legislativo paraense.

Já no Amazonas, a despeito de algumas aprovações de projetos do Executivo na ALEAM, no contexto da pandemia, houve um controle mais efetivo das ações do governador pelos parlamentares e alguns conflitos entre o governador Wilson Lima (PSL) e o presidente da Casa Legislativa, Josué Neto (PSD). O fato mais ilustrativo desses conflitos entre os dois poderes está na instalação da CPI da Saúde, no final de maio de 2020, assim como as discussões de um possível processo de impeachment do chefe do Poder Executivo amazonense.

O segundo aspecto - e que interferiu diretamente também nos processos legislativos - foi o ritmo diferenciado da pandemia no Brasil, atingindo Amazonas e Pará com intensidades e modos distintos. Embora os dois estados tenham enfrentado muitos problemas em relação aos números de casos e de óbitos, no período analisado, o Amazonas entrou em colapso dos sistemas de funerário mais rapidamente, nos meses de abril e maio de 2020. No Pará, o pico da pandemia esteve entre a segunda quinzena de maio e a primeira semana de junho. Mesmo as ações legislativas tendo sido relativamente satisfatórias, os estados tiveram muitas dificuldades de enfrentar a pandemia, até mesmo pela precariedade na infraestrutura sanitária das unidades federativas e as falhas no processo de distanciamento social. As ações integradas no Pará também foram mais rápidas e efetivas do que no Amazonas.

O outro aspecto de diferença está ligado à própria característica geográfica e populacional do Pará e do Amazonas. O Pará tem pouco mais de oito 8 milhões de habitantes, com uma densidade demográfica relativamente baixa $\left(6,87 \mathrm{hab} / \mathrm{km}^{2}\right)$. Já o Amazonas tem pouco mais de quatro milhões de habitantes, com uma densidade demográfica muito mais baixa (2,66 hab/ $\left./ \mathrm{km}^{2}\right)$, sendo que Manaus concentra a metade da população.

Nos números gerais da Covid-19, na primeira onda doença, o Pará registrou pouco mais de 200 mil casos, entre março e agosto de 2020, com quase 6.200 mortes; o Amazonas apresentou, no período avaliado, pouco mais de 120 mil casos, com cerca de 3.700 mortes $^{15}$.

\footnotetext{
${ }^{15}$ Os dois estados, durante a primeira onda da doença, no período avaliado, tiveram resultados muito ruins no combate à doença, mas os índices do Amazonas são, proporcionalmente, piores. Informações disponíveis em https://g1.globo.com/am/amazonas/noticia/2020/08/31/am-confirma-mais-10-mortes-por-covid-19-e-numero-deobitos-sobe-para-3649.ghtml. Acesso em: 20 ago. 2020.
} 
Por fim, registra-se que as reuniões dos plenários virtuais das casas legislativas dos estados foram importantes para a sequência dos trabalhos parlamentares e para o exame de projetos de leis do Poder Executivo e dos próprios deputados estaduais. A aprovação rápida do estado de calamidade, em ambos os estados, pelas Assembleias Legislativas, também foi um movimento importante dentro das premissas constitucionais plenamente definidas pelo STF.

\section{Conclusões}

A partir dos elementos expostos, é possível afirmar, à guisa de conclusões, que as Assembleias Legislativas do Pará e do Amazonas - formadas, respectivamente, por 41 e por 24 deputados estaduais - buscaram agir, dentro de suas atribuições institucionais previstas, de forma rápida em criar condições para que os Poderes Executivos pudessem desenvolver, de maneira efetiva, o enfrentamento à pandemia.

Não foram processos fáceis - e Pará e Amazonas enfrentaram muitas dificuldades, mesmo que em momentos diferentes, em relação à expansão da pandemia no Brasil e na Região Norte. Identificam-se que as assembleias buscaram agir de forma responsiva para o enfrentamento da crise, com uma relação mais equilibrada entre Executivo e Legislativo no Pará e mais conflitos entre os dois poderes no Amazonas no contexto da crise.

Observou-se, portanto, uma interação mais linear dos Poderes Executivo e Legislativo no estado do Pará, enquanto que, no Amazonas, a despeito de algumas ações relativamente rápidas da ALEAM, os conflitos com o Executivo vieram mais à tona, dificultando a cooperação estratégica dos atores institucionais no enfrentamento à pandemia de modo mais assertivo. A CPI da Saúde e a abertura do processo do impeachment do governador amazonense, Wilson Lima, ilustram bem esses conflitos.

As duas Assembleias Legislativas foram relativamente rápidas na aprovação de empréstimos e de projetos do Executivo, e também criaram comissões para o acompanhamento das despesas e dos valores investidos no enfrentamento da pandemia.

Houve diferenças nos processos, a partir das especificidades de cada relação entre Executivo e Legislativo nas duas unidades federativas, mas o nível de enfrentamento geral e um certo protagonismo da classe parlamentar foram similares. As trajetórias divergentes estiveram associadas ao fato, principalmente, de um cenário de maior conflito no Amazonas, com a contestação do Executivo pelo Legislativo, enquanto que no Pará se percebeu um trabalho de parceria.

Nesse mesmo sentido, é importante ressaltar que o Amazonas sofreu de forma mais precoce o mesmo processo de expansão da pandemia - entre abril e maio -, enquanto que o Pará passou pelo seu pior período no mês de junho. No segundo semestre de 2020, após um certo 
período de controle da doença, os dois estados voltaram a conviver com as consequências do vírus, em uma "segunda onda" da pandemia.

Nas categorias conceituais de accountability e responsiveness, há a identificação clara de que o Poder Legislativo no Pará e no Amazonas buscaram uma linha de prestação de contas e de fiscalização em relação ao Poder Executivo, da mesma fora que representaram mais uma instituição essencial de busca de respostas rápidas por parte da gestão das respectivas unidades federativas. Como se mostrou no texto, houve algumas fissuras nesse processo, mas houve a observância, mesmo que parcial, das duas perspectivas conceituais.

As condições observadas mostraram uma coincidência dos sistemas de saúde (responsiveness), com a limitação das estruturas básicas para o atendimento ao público; e a percepção de possíveis atos de corrupção (accountability).

Assim, diante do exposto, considerando-se as semelhanças e diferenças e os conceitos aqui operacionalizados, o Brasil, como um todo, perdeu a guerra contra a Covid-19, com números exponenciais de contaminações e mortes, durante todo o ano de 2020. Pará e Amazonas estão nesse contexto, mas seus poderes legislativos, dentro de suas especificidades e limitações, buscaram cumprir suas funções constitucionais e contribuíram, de alguma forma, para a amenização dos efeitos graves da crise sistêmica que atingiu o país.

\section{Referências}

ALEAM aprova por unanimidade calamidade pública no Amazonas até 31 de dezembro deste ano. 2020. Portal ONJORNAL. Disponível em: https://onjornal.com/aleam-aprova-porunanimidade-calamidade-publica-no-amazonas-ate-31-de-dezembro-deste-ano/. Acesso em: 10 ago. 2020.

ALEAM ouve, na segunda (8), comunidade científica sobre retorno das atividades presenciais.2020. Portal Informe Amazonas. Disponível em: https://informeamazonas.com.br/aleam-ouve-segunda-8-comunidade-cientifica-sobre-retornodas-atividades-presenciais/. Acesso em: 10 ago.2020.

ALEPA aprova crédito para combate à pandemia e estabelece multa para fake news. 2020. Portal ALEPA. Disponível em: https://g1.globo.com/pa/para/noticia/2020/05/07/alepa-aprova-creditopara-combate-a-pandemia-e-estabelece-multa-para-fake-news.ghtml. Acesso em: 10 ago.2020.

ALEPA aprova empréstimo para combater pandemia e estabelece multa para "fake news". 2020. Portal ALEPA. Disponível em: www.alepa.pa.gov.br/noticia/3963/. Acesso em: 10 ago.2020.

ALEPA aprova projetos de combate à pandemia. 2020. Portal ALEPA. Disponível em: www.alepa.pa.gov.br/noticia/3933/. Acesso em: 10 ago.2020

ALEPA participa de live da transparência, processo legislativo e participação popular na pandemia. 2020. Portal ALEPA. Disponível em: www.alepa.pa.gov.br/noticia/4282/. Acesso em: 5 set. 2020. 
ALVES, Sandra Mara Campos; RAMOS, Edith Maria Barbosa; DELDUQUE, Maria Célia. Decretação de lockdown pela via judicial: medida (des)necessária? Cadernos de Saúde Pública, v. 36, n. $6,2020$.

AM confirma mais 10 mortes por Covid-19 e número de óbitos sobe para 3.649. 2020. Portal G1. Disponível em: https://g1.globo.com/am/amazonas/noticia/2020/08/31/am-confirma-mais10-mortes-por-covid-19-e-numero-de-obitos-sobe-para-3649.ghtml. Acesso em: 20 ago. 2020.

ARAÚJO FILHO, Luiz Paulo da Silva. A tutela jurisdicional dos direitos fundamentais sociais e as políticas públicas. Rio de Janeiro: TRF2, EMARF, 2019, 262 p. Disponível em: https://emarf.trf2.jus.br/site/documentos/livrotuteladireitos2019.pdf. Acesso em: 20 nov. 2020.

ARRETCHE, Marta. Relações federativas nas políticas sociais. Educação \& Sociedade, Campinas, SP, v. 23, n. 80, p. 25-48, set. 2002.

BORDALO apresenta seis ações emergenciais ao governo em tempo de pandemia. 2020. Portal ALEPA. Disponível em: www.alepa.pa.gov.br/noticiadep/3891/106. Acesso em: 15 ago.2020.

BRASIL. [Constituição (1988)]. Constituição da República Federativa do Brasil. Disponível em: http://www.planalto.gov.br/ccivil_03/Constituicao/ConstituicaoCompilado.htm. Acesso em: 15 ago. 2020 .

BRASIL. Ministério da Saúde. Coronavírus Brasil. 2020. Disponível em: https://covid.saude.gov.br/. Acesso em: 9 set. 2020.

CCJ aprova projetos de medidas para a pandemia, escalpelamento e de combate a violência feminina. 2020. Portal ALEPA. Disponível em: www.alepa.pa.gov.br/noticia/4232/. Acesso em: 10 ago.2020.

DECISÃO do STF sobre isolamento de estados e municípios repercute no Senado. 2020. Portal do Senado Federal. Disponível em: www12.senado.leg.br/noticias/materias/2020/04/16/decisao-do-stf-sobre-isolamento-deestados-e-municipios-repercute-no-senado. Acesso em: 20 jun. 2020.

DIEHL, Astor; TATIM, Denise. Pesquisa em Ciências Sociais Aplicadas: métodos e técnicas. São Paulo: Prentice Hall, 2004.

DEPUTADOS aprovam projetos para atender ações de combate à pandemia. 2020. Portal ALEPA. Disponível em: www.alepa.pa.gov.br/noticia/3906/. Acesso em: 10 ago.2020.

DEPUTADOS aprovam projeto que reabre igrejas durante pandemia no Amazonas. 2020. Portal UOL. Disponível em: https://noticias.uol.com.br/cotidiano/ultimasnoticias/2020/05/06/deputados-aprovam-projeto-que-reabre-igrejas-durante-pandemia-noamazonas.htm. Acesso em: 10 ago.2020.

DEPUTADOS estaduais discutem ações de combate à pandemia no Amazonas. 2020. Portal Diversidade Amazônica. Disponível em: https://diversidadeamazonica.com.br/2020/04/28/deputados-estaduais-discutem-acoes-decombate-a-pandemia-no-amazonas/. Acesso em: 10 ago.2020.

DEPUTADOS instalam comissão parlamentar para fiscalizar ações do executivo no combate à pandemia. 2020. Portal ALEPA. Disponível em: www.alepa.pa.gov.br/noticia/3889/. Acesso em: 10 ago.2020. 
DILVANDA Faro apresenta projetos para enfrentamento da pandemia no Pará.2020. Portal ALEPA. Disponível em: www.alepa.pa.gov.br/noticiadep/4248/115. Acesso em: 10 ago.2020.

DUNN, Delmer. Mixing elected and non-elected officials in democratic policy making: fundamentals of accountability and responsibility. In: PRZEWORSKI, Adam; SOTOKES, Susan C.; MANIN, Bernard (ed.). Democracy, Accountability and Representation. Cambridge: Cambridge University Press, 1999.

EMERGÊNCIA em saúde e estado de calamidade: veja diferença. 2020. Agência Brasil. Disponível em: https://agenciabrasil.ebc.com.br/saude/noticia/2020-03/emergencia-em-saude-eestado-de-calamidade-veja-diferenca. Acesso em: 9 set. 2020.

GONZÁLEZ, Rodrigo. O método comparativo e a ciência política. Revista de Estudos e Pesquisas Sobre As Américas, n. 2, 2008. Disponível em: https://periodicos.unb.br/index.php/repam/article/view/16160. Acesso em: 20 jun. 2020.

GOVERNMENT ACCOUNTABILITY OFFICE (GAO). Normas de auditoria governamental. Salvador: Tribunal de Contas do Estado da Bahia, 2005.

HÖFFE, Otfried. A democracia no mundo de hoje. São Paulo: Martins Fontes, 2005.

IMPEACHMENT de governador do Amazonas é aberto na Assembleia. 2020. Portal Terra. Disponível em: www.terra.com.br/noticias/coronavirus/impeachment-de-governador-doamazonas-e-aberto-na-assembleia,11 fbad80be9de880462d5dbfc96c6f05p0cgsuq8.html. Acesso em: 20 ago. 2020 .

LIMONGI, Fernando; FIGUEIREDO, Argelina. Processo orçamentário e comportamento legislativo: emendas individuais, apoio ao Executivo e programas de governo. Dados: Revista de Ciências Sociais, Rio de Janeiro, v. 48, n. 4, p. 737-776, 2005.

LEITE. Breno Rodrigo Messias. Como os governos estaduais lidam com a pandemia. 2020. Disponível em: www.nexojornal.com.br/especial/2020/05/10/Como-os-governos-estaduaislidam-com-a-pandemia, 2020. Acesso em: 20 ago. 2020.

LEITE. Breno Rodrigo Messias. Especial ABCP: ações do estado do Amazonas no enfrentamento da pandemia. 2020. Disponível em: https://cienciapolitica.org.br/noticias/2020/06/especial-abcp-acoes-amazonas-enfrentamentopandemia. Acesso em: 20 ago.2020.

MARTINES JÚNIOR, Eduardo. Accountability, Responsiveness e Ministério Público. Caderno de Administração: Revista do Departamento de Administração da FEA, v. 1, 2016. Disponível em: https://revistas.pucsp.br/caadm/article/view/19127. Acesso em: 5 set. 2020.

MOISÉS, José Álvaro. Confiança na Democracia e Desconfiança das Instituições Democráticas. In: MOISÉS, José Álvaro (org.). Democracias e Confiança: Por que os Cidadãos Desconfiam das Instituições Públicas? São Paulo: Editora da Universidade de São Paulo, 2010.

O’DONNELL, Guillermo. Accountability horizontal e novas poliarquias. São Paulo: Lua Nova, 1998.

OMS decreta pandemia do novo coronavírus. 2020. Portal Saúde Abril. Disponível em: https://saude.abril.com.br/medicina/oms-decreta-pandemia-do-novo-coronavirus-saiba-o-queisso-significa/. Acesso em: 5 dez. 2020. 
PANDEMIA do coronavírus preocupa parlamento paraense. 2020. Portal ALEPA. Disponível em: www.alepa.pa.gov.br/noticia/3833/. Acesso em: 15 ago.2020.

PROCURADORIA especial da ALEPA faz live sobre a violência contra a mulher na pandemia. 2020. Portal ALEPA. Disponível em: www.alepa.pa.gov.br/noticia/3942/. Acesso em: 10 ago.2020.

SIU, Marx Chi Kong. Accountability no setor público: uma reflexão sobre transparência governamental no combate à corrupção. Revista do TCU, n. 6, p. 80-89, 2011. Disponível em: https://revista.tcu.gov.br/ojs/index.php/RTCU/article/view/197. Acesso em: 10 set. 2020.

SOARES, Márcio. Teoria do sistema federal: heterogeneidades territoriais, democracia e instituições políticas. 1997. Dissertação (Mestrado) - Universidade Federal de Minas GeraisUFMG, 1997.

TRANSPARÊNCIA nos gastos do Governo com a pandemia. 2020. Portal ALEPA. Disponível em: www.alepa.pa.gov.br/noticiadep/4099/111. Acesso em: 5 set. 2020.

TECNOLOGIA e compromisso para manter o Poder Legislativo atuante na pandemia. 2020. Portal ALEPA. Disponível em: www.alepa.pa.gov.br/noticia/4207/. Acesso em: 5 set.2020. 